\title{
Mathematics Classroom Studies: Multiple Lenses and Perspectives
}

\author{
Berinderjeet Kaur
}

\begin{abstract}
In some ways, the Third International Mathematics and Science Study (TIMSS) Video Studies of 1995 and 1999 may be said to be the impetus for classroom studies in many countries. These studies created an awareness of how vast video data and how endless the possibilities of rich analysis were. They also stimulated thought and academic discourse about the conceptual framework and methodology, which led to subsequent video studies such as the Learner's Perspective Study (LPS). This paper recounts how mathematics classroom studies have developed over the past decades in Singapore. It shows that the use of particular types of lenses does have an impact on images of mathematics teaching that emerge from the analysis. It also examines the stereotype of East Asian mathematics classroom instruction and suggests that instructional practices for mathematics classrooms cannot be considered Eastern or Western but a coherent combination of both.
\end{abstract}

Keywords TIMSS video studies • Learner's perspective study • Mathematics classroom studies in Singapore · East Asian pedagogy • Models of instruction

\section{Background}

In some ways, the Third International Mathematics and Science Study (TIMSS) Video Studies of 1995 (Stigler \& Hiebert, 1999) and 1999 (Hiebert et al., 2003) may be said to be the impetus for classroom studies in many countries. These studies created an awareness of the vastness of video data and the possibilities of endless rich analysis. They also stimulated thought and academic discourse about the conceptual framework and methodology of such studies, which led to subsequent video studies such as the Learner's Perspective Study (LPS; Clarke, Keitel, \& Shimizu, 2006).

\footnotetext{
B. Kaur $(\bowtie)$

National Institute of Education, Singapore, Singapore

e-mail: berinderjeet.kaur@nie.edu.sg

(C) The Author(s) 2017

G. Kaiser (ed.), Proceedings of the 13th International Congress on Mathematical

Education, ICME-13 Monographs, DOI 10.1007/978-3-319-62597-3_4
} 
Three countries, Germany, Japan and the United States, participated in the TIMSS 1995 Video Study. Eighth-grade mathematics lessons were studied and national samples of teachers in the three countries participated. One lesson per teacher was recorded. Altogether 100 lessons in Germany, 50 in Japan and 81 in the United States were recorded. A significant finding of the study was that:

To put it simply, we are amazed at how much teaching varied across cultures and how little it varied within cultures ... Teaching is a cultural activity. We learn how to teach indirectly through years of participation in classroom life, and we are largely unaware of the most widespread attributes of teaching in our own culture. (Stigler \& Hiebert, 1999, p. 11)

The study adopted a big-picture perspective and created portraits of eighth-grade mathematics lessons in the three countries. Figure 1 shows the patterns of teaching in the three countries.

The study also made generalisations such as the following:

American mathematics teaching is extremely limited, focussed for the most part on a very narrow band of procedural skills. Whether students are in rows working individually or sitting in groups, whether they have access to the latest technology or are working only with paper and pencil, they spend most of their time acquiring isolated skills through repeated practice. (Stigler \& Hiebert, 1999, p. 10)

Japanese teaching is distinguished not so much by the competence of the teachers as by the images it provides of what it can look like to teach mathematics in a deeper way: teaching for conceptual understanding. Students in Japanese classrooms spend as much time solving challenging problems and discussing mathematical concepts as they do practicing skills (Stigler \& Hiebert, 1999, p. 11).

These generalisations, which resulted from the coding schemes developed for the study, were not helpful in explaining the what and how of mathematics instruction in the three countries.

\begin{tabular}{|c|c|c|}
\hline $\begin{array}{l}\text { The German Pattern } \\
\text { [4 activities] } \\
\text { 1. Reviewing previous } \\
\text { material } \\
\text { 2. Presenting the topic and } \\
\text { problems for the day } \\
\text { 3. Developing procedures } \\
\text { to solve problem(s) } \\
\text { 4. Practicing }\end{array}$ & $\begin{array}{l}\text { The Japanese Pattern } \\
\quad \text { [5 activities] } \\
\text { 1. Reviewing the previous } \\
\text { lesson } \\
\text { 2. Presenting the problem } \\
\text { for the day } \\
\text { 3. Students working } \\
\text { individually or in groups } \\
\text { 4. Discussing solution } \\
\text { methods } \\
\text { 5. Highlighting and } \\
\text { summarising the major } \\
\text { points }\end{array}$ & $\begin{array}{l}\text { The U.S. Pattern } \\
\text { [4 activities] } \\
\text { 1. Reviewing previous } \\
\text { material } \\
\text { 2. Demonstrating how to } \\
\text { solve problems for the } \\
\text { day } \\
\text { 3. Practicing } \\
\text { 4. Correcting seatwork and } \\
\text { assigning homework }\end{array}$ \\
\hline
\end{tabular}

Fig. 1 Big picture perspective: patterns of teaching (Stigler \& Hiebert, 1999, pp. 78-81) 
The TIMSS 1999 Video Study (Hiebert et al., 2003) not only involved more countries but also expanded the scope of the previous video study. Seven countries, Australia, Czech Republic, Hong Kong SAR, Japan, Netherlands, Switzerland and the United States, were involved in the study. The method of data collection was similar to the past study. However, several changes were made to the process of analysing the data. Recognising the limitations of big picture perspectives using the wide-angle lens approaches in the past study, the TIMSS 1999 Video Study added close-up lens approaches for meaningful interpretations of findings (Hiebert et al., 2003). When comparing mathematics teaching across countries, a close-up lens provides a more in-depth and nuanced perspective to the similarities in teaching. It makes apparent aspects such as the problems students solve and how they solve them.

Most importantly, the study made a significant contribution towards comparative studies on mathematics teaching by encouraging readers to digest the contents of the report(s) arising from the study and engage in 'more nuanced international discussions of mathematics teaching' (Hiebert et al., 2003, p. 13). One study that arose from such international discussions was the Learner's Perspective Study (Clarke et al., 2006).

\section{The Early Stages of Mathematics Classroom Studies in Singapore: The 1990s}

The good performance of Singapore students in the Third International Mathematics and Science Study (TIMSS) 1995 (Mullis et al., 1997; Beaton et al., 1997) and also subsequent Trends in International Mathematics and Science Studies (TIMSS) (Mullis et al., 2000; Mullis, Martin, Gonzalez, \& Chrostowski, 2004; Mullis, Martin, Foy, \& Arora, 2012; Mullis, Martin, \& Foy, 2008) has drawn a lot of attention to the teaching and learning of mathematics in Singapore schools. Educators in Singapore have also become more curious about activities in their mathematics classrooms. Two studies amongst the few that may be considered to be the first to document activities in mathematics classrooms were the Kassel Project (Kaur \& Yap, 1997) and A Study of Grade 5 Mathematics Lessons (Chang, Kaur, Koay, \& Lee, 2001). In the proceeding subsections the studies are detailed.

\section{Kassel Project (1995-1996)}

The Kassel project (Kaur \& Yap, 1997) was an international comparative project on the teaching and learning of mathematics helmed by the Centre for Innovation in Mathematics Teaching at the University of Exeter. It was Prof Gabriele Kaiser who initiated Singapore's participation in the project. As part of the project, 21 Grade 8 
mathematics lessons in 1995 and 22 Grade 9 mathematics lessons in 1996 were observed by Professor Kaur and Dr Yap at the National Institute of Education (NIE). Lesson review sheets, shown in Fig. 2, were used to document observations.

A glossary of terms, resulting in a shared vocabulary, was created by the two researchers who observed the lessons to write the lesson narratives. Table 1 shows part of the glossary. In this paper, only the data for the 21 Grade 8 mathematics lessons observed in seven schools is presented. The lesson narratives were coded and descriptive statistics used to arrive at the findings (see Kaur \& Yap, 1997 for details of the coding and descriptive statistics).

The wide-angle lens findings of the study tell us that the teachers were task oriented, presented knowledge by telling and explaining and demonstrated how to solve mathematical problems (step by step and placed more emphasis on procedures, answers and accuracy than on concepts and processes). They were enthusiastic about their teaching, had high expectations of their pupils, handled the mathematics confidently, gave instructions that were candid and clear and their lessons were highly structured with specific achievable objectives. They almost always assigned homework and graded it. They used the chalkboard, textbook and overhead projector to assist them in their classroom instruction. Their students were quiet, appeared attentive (even though at times teacher talk was too lengthy to sustain student attention), looked happy, seldom volunteered responses or raised doubts and were task-oriented and receptive to the teaching.

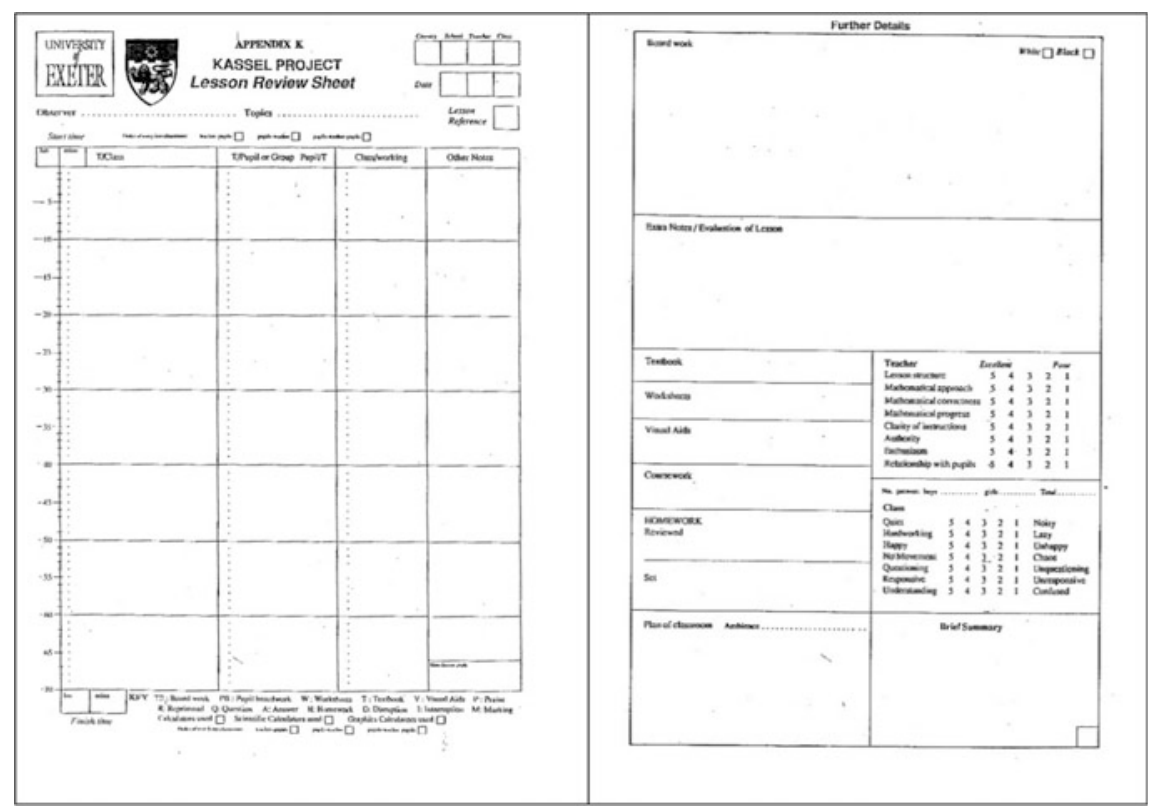

Fig. 2 Lesson review sheets 
Table 1 Glossary of terms

\begin{tabular}{l|l}
\hline Term & Explanation \\
\hline Teacher exposition & Teacher presents knowledge by telling and explaining \\
\hline $\begin{array}{l}\text { Teacher } \\
\text { demonstration }\end{array}$ & $\begin{array}{l}\text { Teacher works solution to a task highlighting procedure and explaining } \\
\text { how the procedure is used }\end{array}$ \\
\hline $\begin{array}{l}\text { Deductive } \\
\text { questioning }\end{array}$ & $\begin{array}{l}\text { Teacher asks a sequence of questions which guide pupils to form ideas by } \\
\text { reasoning and drawing on prior knowledge }\end{array}$ \\
$\ldots$ & $\ldots$ \\
\hline $\begin{array}{l}\text { Whole class } \\
\text { discussion }\end{array}$ & $\begin{array}{l}\text { Teacher structures the flow of the interaction and directs students' } \\
\text { involvement and participation; teacher is responsible to ensure that there } \\
\text { is a central focus of discussion and that questions keep coming back to } \\
\text { the key issue(s) }\end{array}$ \\
\hline$\ldots$ & $\ldots$ \\
\hline Direct questions & Questions which call for recall of knowledge (facts/algorithms) \\
\hline$\ldots$ & $\ldots$ \\
\hline $\begin{array}{l}\text { Seatwork } \\
\text { (individual/pair) }\end{array}$ & Pupils do mathematical tasks in class on their own/in pairs \\
\hline
\end{tabular}

\section{A Study of Grade 5 Mathematics Lessons (1998-1999)}

This was a small-scale study to investigate the pedagogical practices of Grade 5 mathematics teachers in Singapore (Chang et al., 2001). Lesson observations using lesson review sheets and self-reports by teachers about how they taught a lesson were deemed unsuitable for the study. In lesson observations, based on the experience of the Kassel project, the researchers (observers) found it difficult to observe and note all that was happening in the class concurrently. In self-reports, due to the lack of a shared vocabulary, it is difficult to know how accurately the teachers document their lessons and what they mean by the words they use; for example, if a teacher says she did 'problem solving' with her students, what exactly did she do? Different teachers may use the same word to mean different things. Therefore, this study video-recorded mathematics lessons and may be considered to be the first to do so in Singapore. The study investigated the pedagogical practices of Grade 5 mathematics teachers following two initiatives, namely the infusion of thinking skills and the use of information technology in Singapore schools. Four Grade 5 teachers from two schools (two from each school) with distinctively different student profiles participated in the study. Altogether 5 one-hour lessons were recorded. Teachers were also interviewed about their lessons.

For the first phase of the data analysis, a wide-angle lens was adopted. The researchers were interested in locating at the macro-level: (i) similarities and differences in the lessons in the two schools and (ii) the impact of the initiatives (thinking skills \& IT) on the pedagogy of the teachers. The findings of this phase were that in both schools, lessons were mainly teacher directed with two thirds of the lesson time devoted to teacher talk and a third to student work (individually or 
group-work). Student talk consisted of answering teacher-initiated questions or seeking clarifications. The tasks enacted during the lessons mainly encouraged comprehension and application of knowledge. Furthermore, classwork and homework focused mainly on development of skills and use of knowledge to complete routine tasks and prepare for examinations. In School A, where the students were of high ability, students were also provided with enrichment activities, but the activities were not tailored to enhance any specific thinking strategies or skills. Regarding the impact of the initiatives, in both schools lessons were teacher directed with little or no evidence of activities to engage students in thinking or development of any thinking strategies, and the infusion of technology in the lessons was also not evident.

For the second phase of data analysis, it was planned that a close-up lens would be used to examine in depth the similarities of teaching in the classrooms of all the four teachers. However, due to an incident the video data was unavailable for analysis.

\section{The Learner's Perspective Study}

The Learner's Perspective Study (LPS) is an international study helmed by Professor David Clarke at the University of Melbourne. It stated in 1999 with Australia, Germany, Japan and the USA examining the practices of eighth-grade mathematics classrooms in a more integrated and comprehensive manner than had been attempted in past international studies, in particular the TIMSS Video Studies of 1995 and 1999. The study has several distinguishing features amongst which are (a) documentation of a sequence of lessons rather than just single lessons, (b) the exploration of learner practices and (c) use of the complementary accounts methodology developed by Clarke (1998) for data collection of classroom practice - an activity where both teacher and students are key participants (Clarke et al., 2006).

Singapore's participation in the LPS marked the start of using video data to explore perspectives of mathematics teaching in a comprehensive manner. Singapore joined the LPS in 2004. The main objectives of the study in Singapore were to (a) document practices of competent mathematics teachers in Grade 8 mathematics classrooms, (b) study from the perspectives of students the roles of the textbook and homework and what constitutes good mathematics lessons and (c) identify common classroom pedagogies from the perspectives of both teachers and students that enhance the teaching and learning of mathematics (Kaur \& Low, 2009).

Three mathematics teachers, T1, T2 and T3, recognised by their local communities for 'teaching competence', and their respective classes of Grade 8 students participated in the study (see Kaur, 2009 for details). In the following subsections some selected data and findings of mathematics teaching in Grade 8 classrooms are presented. 


\section{Instructional Approaches}

The video records of the 10-lesson sequence for each of the teachers were the main source of the data analysed. For the first phase of the data analysis, a wide-angle lens was adopted. The researchers viewed the video records and located global features related to the patterns of instruction of the three teachers. For the second phase of the data analysis, a close-up lens was used and the grounded theory approach was adopted. An activity segment, 'the major division of the lessons', served as an appropriate unit of analysis for examining the structural patterns of lessons since it allowed us 'to describe the classroom activity as a whole' (Stodolsky, 1988, p.11). According to Stodolsky:

In essence, an activity segment is a part of a lesson that has a focus or concern and starts and stops. A segment has a particular instructional format, participants, materials, and behavioural expectations and goals. It occupies a certain block of time in a lesson and occurs in a fixed physical setting. A segment's focus can be instructional or managerial. (Stodolsky, 1988, p. 11)

For the purpose at hand, the activity segments were distinguished mainly by the instructional format that characterised them, although there were other segment properties, such as materials that differed among the various activity segments identified. Six categories of activity segments emerged through reiterative viewing of the video data. These mutually exclusive segments were found to account for most of the 30 lessons, 10 each from T1, T2 and T3. Table 2 shows the categories and Table 3 shows the analysis of lesson structure with mathematical content of T2.

Coding of the video data revealed patterns of instructional cycles that consisted mainly of combinations of the three main categories of classroom activity: whole-class demonstration [D], seatwork [S] and whole-class review of student work [R] for the sequences of 10 lessons each for T1, T2 and T3. Figure 3 shows the segment sequence for the 10 lessons each for T1, T2 and T3. Activity segments that served different instructional objectives were separated by a dotted vertical line. In an instructional cycle, the mathematical tasks shared the same instructional objective.

Table 2 Categories of activity segments

\begin{tabular}{l|l}
\hline $\begin{array}{l}\text { Whole-class } \\
\text { demonstration [D] }\end{array}$ & $\begin{array}{l}\text { Whole-class mathematics instruction that aimed to develop } \\
\text { students' understanding of mathematical concepts and skills }\end{array}$ \\
\hline Seatwork [S] & $\begin{array}{l}\text { Students were assigned questions to work on either individually } \\
\text { or in groups at their desks }\end{array}$ \\
\hline $\begin{array}{l}\text { Whole-class review of } \\
\text { student work [R] }\end{array}$ & $\begin{array}{l}\text { Teachers' primary focus was to review the work done by } \\
\text { students or the task assigned to them }\end{array}$ \\
\hline Miscellaneous [M] & $\begin{array}{l}\text { A catch-all category during which the class was involved in } \\
\text { managerial and administrative activities }\end{array}$ \\
\hline Group quiz [Q] & $\begin{array}{l}\text { Found in T2's lessons; students solved tasks in groups in a } \\
\text { competitive manner }\end{array}$ \\
\hline Test [T] & Found only in the lessons of T1 and T3 \\
\hline
\end{tabular}




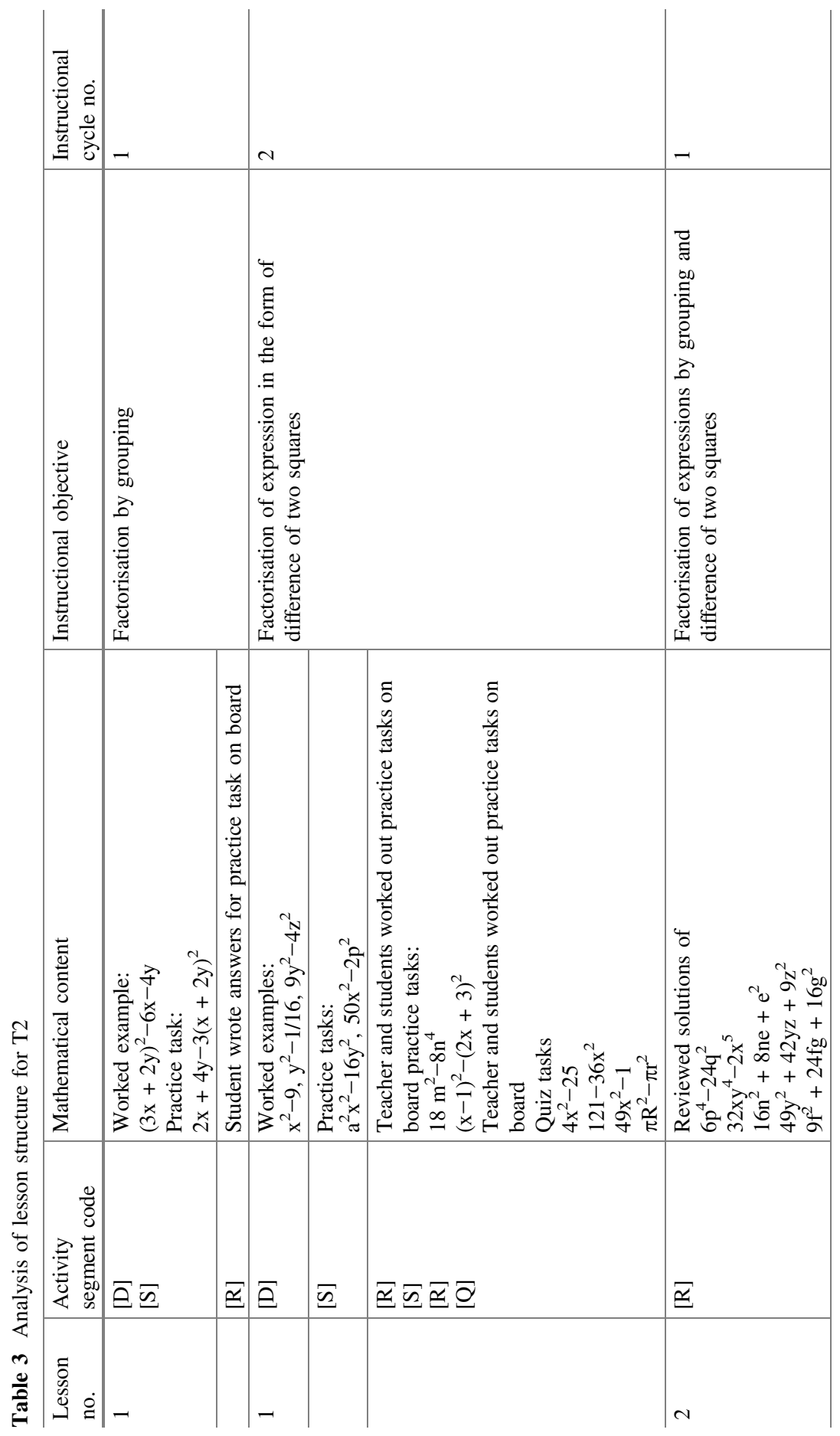


Teacher 1 [T1] (School 1)

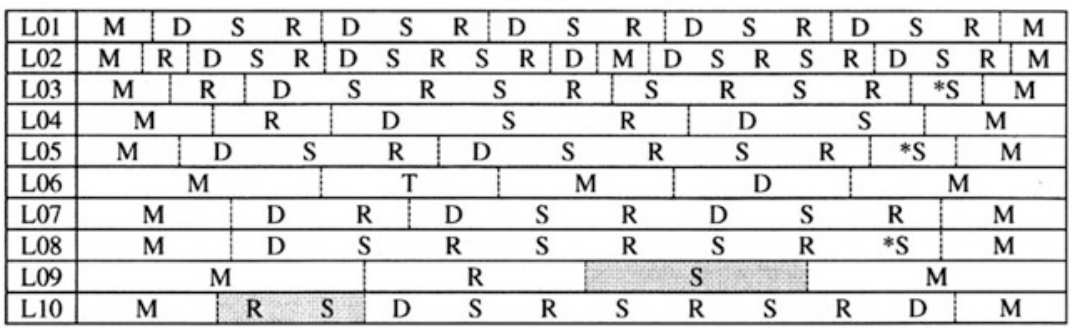

Teacher 2 [T2] (School 2)

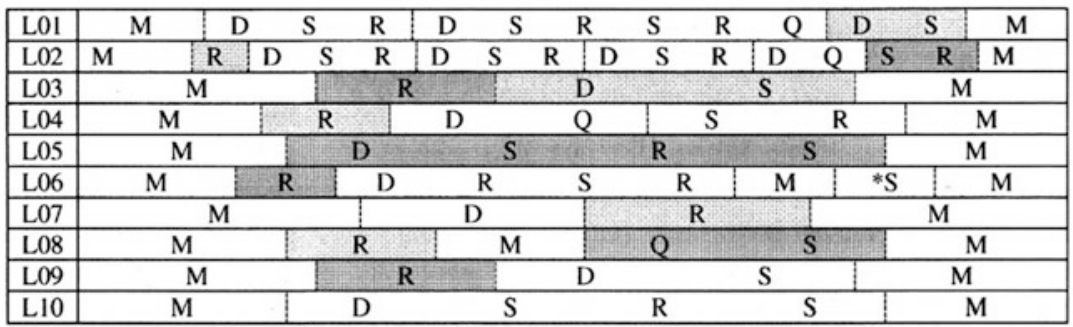

Teacher 3 [T3] (School 3)

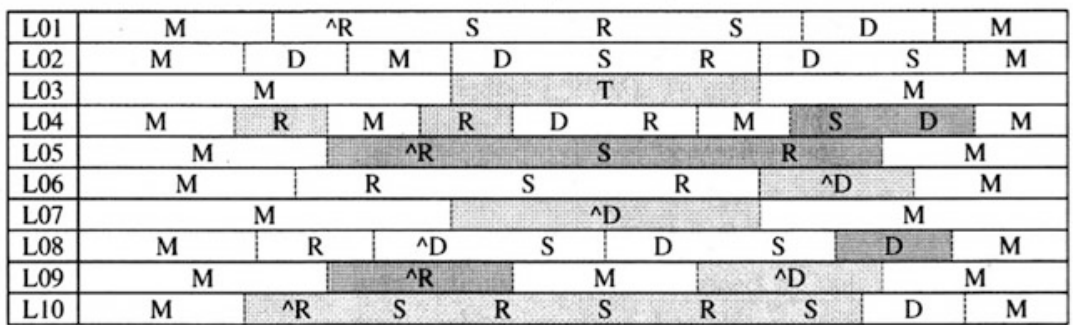

Legend

Represents the border between instructional cycles

* Time-filler

$\wedge$ Segment with interruption

Shaded regions represent the same cycles across adjacent lessons.

Note: The lengths of segments do not reflect their duration within the lesson.

Fig. 3 Structural patterns of the lesson sequences of T1, T2 and T3

To understand the instructional approaches further, it is necessary to go beyond structural patterns of the lesson sequence. The key features of the classroom talk through which the teachers realised their roles in not just the teaching of mathematics but also in engaging students to learn it are described elsewhere (see Kaur, 2009). 
The wide-angle lens findings show that the pattern of instruction in the Grade 8 classrooms of the three competent teachers was as follows: (1) Set the stage for a topic/review past knowledge, (2) present a concept/procedure and show how to work out the solution of a problem, (3) do seatwork and (4) correct seatwork and assign homework. Lessons were also deemed to be teacher-centred, mainly comprising teacher exposition coupled with student practice. This is often interpreted as 'drill and practice' by many who have no other information about the what and the how of the lessons. On the contrary, the close-up lens findings show that lessons consisted of instructional cycles that were highly structured combinations of D, S and R. Specific instructional objectives guided each instructional cycle, with subsequent cycles building on the knowledge. Carefully selected examples that systematically varied in complexity from low to high were used during whole-class demonstrations. There was also active monitoring of student's understanding during seatwork (teachers moved from desk to desk guiding those with difficulties and selecting appropriate student work for subsequent whole-class review and discussion). Most importantly, student understanding of knowledge expounded during whole-class demonstrations was reinforced by detailed review of student work done in class or as homework, and lessons were both teacher and student centred.

\section{Students'Perceptions of Their Teachers' Teaching}

A distinguishing feature of the LPS is the exploration of learner practices using post-lesson video-stimulated interviews. The interviews of the 'focus students' consisted of two parts. The first part was based on the video record of the lesson for which they were the focus students. The second part was stimulated by several prompts. Fifty-nine students were interviewed: 19 from T1's class, 20 from T2's class and 20 from T3's class. The interview transcripts of the 59 students to two prompts in the second part of the interview were the source of the data analysed. The two prompts were:

- Would you describe that lesson as a good one for you?

- What has to happen for you to feel that a lesson was a 'good' lesson?

For all three teachers, T1, T2 and T3, 94, 85 and $84 \%$ of their students, respectively, felt that the lesson for which they were the 'focus students' was a good one. A close-up lens was used and the grounded theory approach adopted to analyse the responses to the second prompt. Three categories and 12 subcategories were derived for coding the responses (see Kaur, 2008 for details). Table 4 shows the categories and subcategories.

Analysis of the interview responses using a close-up lens revealed that students deemed a mathematics lesson a good one when some of the following characteristics were present. The teacher 
Table 4 Categories and subcategories for coding teachers' teaching

\begin{tabular}{|c|c|}
\hline Instructional practice & Subcategory \\
\hline $\begin{array}{l}\text { Exposition (whole class } \\
\text { instruction) }\end{array}$ & $\begin{array}{l}\text { EC: teacher explained } \\
\text { D: teacher demonstrated a procedure, 'taught the method' or } \\
\text { showed using manipulatives concepts/relationships } \\
\text { NK: teacher introduced new knowledge } \\
\text { GI: teacher gave instructions (assigned homework/showed how } \\
\text { work should be done/when work should be handed in for grading, } \\
\text { etc.) } \\
\text { RE: teacher used real-life examples during instruction }\end{array}$ \\
\hline Seatwork & $\begin{array}{l}\text { IW: students worked individually on tasks assigned by teacher or } \\
\text { made/copied notes } \\
\text { GW: students worked in groups } \\
\text { M: material used as part of instruction (worksheet or any other } \\
\text { print resource) }\end{array}$ \\
\hline Review and feedback & $\begin{array}{l}\text { PK: teacher reviewed prior knowledge } \\
\text { SP: teacher used student's presentation or work to give feedback } \\
\text { for in-class work or homework } \\
\text { IF: teacher gave feedback to individuals during lesson } \\
\text { GA: teacher gave feedback to students through grading of their } \\
\text { written assignments }\end{array}$ \\
\hline
\end{tabular}

- explained clearly the concepts and steps of procedures;

- made complex knowledge easily assimilated through demonstrations, use of manipulatives and real-life examples;

- reviewed past knowledge;

- introduced new knowledge;

- used student work/group presentations to give feedback to individuals or the whole class;

- gave clear instructions related to mathematical activities for in-class and after-class work;

- provided interesting activities for students to work on individually or in small groups and

- provided sufficient practice tasks for preparation towards examinations.

\section{A Juxtaposition of Teachers' Practice and Students' Perception}

Findings about how competent teachers teach Grade 8 mathematics and their students' perceptions about a good mathematics lesson are essential for the creation of an image of good mathematics teaching. This is exactly what the data and nature of analysis adopted in the Singapore LPS allowed the researchers to do. In so doing, the researchers questioned the stereotype of East Asian mathematics teaching and have been motivated to delve deeper into their classrooms and create a model of 
mathematics teaching in Singapore schools. The next section reports on the research done so far and in progress.

\section{Traditional Teaching and East Asian Countries: Is the East Asian Stereotype an Accurate Guide to the Teaching of Mathematics in Singapore Schools?}

Leung (2001) has noted that mathematics teaching in East Asia is 'predominantly content orientated and exam driven. Instruction is very much teacher dominated and student involvement minimal'. Teaching is 'usually conducted in whole group settings, with relatively large class sizes'. There is 'virtually no group work or activities, and memorization of mathematics is stressed' and 'students are required to learn by rote'. Students are 'required to engage in ample practice of mathematical skills, mostly without thorough understanding' (pp. 35-36). In the following subsection, we examine Grade 9 mathematics instruction in Singapore.

\section{The CORE 2 Study in Singapore}

The CORE 2 Study in Singapore was a study of pedagogical practices in Grade 9 mathematics and English language. The study has been reported on in detail elsewhere (see Hogan, Towndrow, Chan, Kwek, \& Rahim, 2013a). The data reported here is from a nationally representative sample of over 4000 Grade 9 students in approximately 120 mathematics and English classes across $32 \mathrm{sec}$ ondary schools in Singapore collected in 2010. A split-half multi-level sampling strategy was used. In each class, half of the students were randomly assigned to a 230-item survey focused on students' perceptions of instructional practices in mathematics or English language. In this paper, we focus on the four models of instruction explored in the study. The models are Traditional Instruction (TI), Direct Instruction (DI), Teaching for Understanding (TfU) and Co-Regulated Learning Strategies (CRLS). Figure 4 shows the models of instruction and their respective constructs and scales. Tables 5 and 6 show the means and standard deviations of the models, and correlation matrix of the models respectively.

As shown in Table 5, the means for TI, DI, TfU and CRLS are 3.69, 3.67, 3.38 and 3.01, respectively. Although the strength of TI might lead one to conclude that mathematics instruction at least conforms to the East Asian stereotype, the relative strengths of the other instructional strategies suggest otherwise. This conclusion is supported by the high correlations between DI, TI and TfU (shown in Table 6). The substantially lower correlations between TI and DI with CRLS, as shown in Table 6, explains the active instructional role of the teacher in the classroom. An in-depth analysis of the data was shown in Hogan et al. (2013b). As reported in 
Models of Instruction

Traditional Instruction (TI; 5 constructs)

- A focus on worksheets and workbooks (e.g., 'How often does your mathematics/English teacher ask you to do worksheets or workbooks?')

- A focus on textbooks (e.g., 'How often does your mathematics teacher asks you to answer questions from the textbook?')

- Drill and practice of basic facts, rules and procedures (e.g., 'How often does your mathematics/English teacher ask you to drill and practice on basic facts, rules or procedures?')

- A focus on memorization (e.g., 'How often does your mathematics teacher ask you to remember formulae or rules?')

- Exam preparation ('My teacher emphasizes studying problems that may occur in the exams', 'My teacher spends a lot of class time preparing for exams', 'My teacher teaches us test-taking strategies' and 'My teacher emphasizes practicing past year exam papers'.)

Direct Instruction (DI; 5 constructs)

- Maximum learning time (e.g., 'The teacher makes sure that pupils focus on the lesson'.)

Teacher revision (e.g., 'The teacher checks that pupils understand the lesson'.)

- Structure and clarity (e.g., 'The teacher clearly states the objectives of the lesson', 'The teacher organizes information in an orderly way' and 'The teacher explains things very clearly'.)

- Frequency of practice (e.g., 'We spend a lot of time practicing what we learned'.)

Frequency of questioning (e.g., 'The teacher asks the class lots of questions'.)

Teaching for Understanding (TfU; 11 constructs)

- Focus on understanding (e.g., 'The teacher's explanations really help me understand the topic'.)

- Quality of questions (e.g., 'The teacher asks good questions to see if we really understand'.)

- Communicating learning goals and performance standards (e.g., 'The teacher explains the standard of good performance in our tests and exams'.)

- Curiosity and interest (e.g., 'The teacher makes mathematics/English really interesting'.)

- Flexible teaching (e.g., 'The teacher tries different kinds of teaching to help us understand better'.)

- Whole-class discussion (e.g., 'The teacher supports long class discussions about topics'.)

- Collaborative group work (e.g., 'The teacher encourages students to work as a team in group work'.)

- Teacher scaffolding of group work (e.g., 'The teacher shows us how to work together in groups'.)

- Monitoring of student learning (e.g., 'The teacher asks the class questions to see how well we understand the topic at the beginning of the class'.)

- Personal feedback (e.g., 'The teacher gives me personal comments on my homework'.)

- Collective feedback (e.g., 'The teacher gives the class detailed comments on exams or tests'.)

Co-Regulated Learning Strategies (CRLS) consists of three multi-item first-order scales for

self-directed learning: The teacher encourages us to

- set our own learning goals,

- identify strategies to achieve our learning goals and

- check frequently that our work is acceptable.

self-assessment: The teacher

- asks us to grade our own work,

- explains how we can grade our own work,

- expects us to discuss our own grading of our own work and

- encourages us to comment on our own work.

peer-assessment: The teacher

- asks students to grade each other's work, explains how we can grade each other's work, expects us to discuss our grading of each other's work and encourages us to comment on each other's work.

Fig. 4 Models of instruction and their respective constructs/scales 
Table 5 Means and standard deviations (SD) of the models

\begin{tabular}{l|l|l}
\hline Grade 9 mathematics & $\mathrm{N}=1166$ & $\mathrm{SD}$ \\
\hline Instructional model & Mean (1-5) & 0.642 \\
\hline Traditional instruction & 3.69 & 0.670 \\
\hline Direct instruction & 3.67 & 0.602 \\
\hline Teaching for understanding & 3.38 & 0.770 \\
\hline Co-regulated learning strategies & 3.01 & \\
\hline
\end{tabular}

Table 6 Correlation matrix: instructional models

\begin{tabular}{l|l|l|l|l}
\hline Grade 9 Mathematics $(\mathrm{N}=1166)$ & TI & DI & TfU & CRLS \\
\hline Traditional Instruction (TI) & 1 & & & \\
\hline Direct Instruction (DI) & $0.72^{* *}$ & 1 & & \\
\hline Teaching for Understanding (TfU) & $0.58^{* *}$ & $0.70^{* *}$ & 1 & \\
\hline Co-Regulated Learning Strategies (CRLS) & $0.28^{* *}$ & $0.35^{* *}$ & $0.73^{* *}$ & 1 \\
\hline **Significant at $\mathrm{p}<0.01$ level & \multicolumn{5}{|l}{}
\end{tabular}

**Significant at $\mathrm{p}<0.01$ level

Hogan et al. (2013b), resulting from the structural equation modelling (SEM) analysis carried out, the integrated model for all the four instructional strategies is very large and complex. Nevertheless, the goodness-of-fit statistics are exceptionally good. The model is fully recursive - there are no feedback loops from TfU back into TI or DI practices. The internal structure of each of the instructional strategies is remarkably stable. There is a linear, fully recursive sequence to instructional practice that underscores the coherent and hybridic nature of the instructional regime for mathematics in Singapore Grade 9 classrooms.

Therefore, we conjecture that instructional practices for mathematics in Singapore classrooms, based on the data of the CORE 2 study, cannot be considered either Eastern or Western but a coherent combination of both. The basis of our claim is that (i) TI provides the foundation of the instructional order and (ii) DI builds on TI practices and extends and refines the instructional repertoire, while TfU/CRLS practices build on TI and DI practices and extend the instructional repertoire even further in ways that focus on developing student understanding and student-directed learning. It also appears that four instructional practices - two TI practices (exam preparation and textbook focus) and two DI practices (structure and clarity, and revision) - tie or link the four instructional groupings together in an orderly chain of instructional practice. Of the four, exam preparation is the most significant. It is highly generative both directly and indirectly, reaching well beyond its own close family of TI practices into DI and TfU practices.

In addition, there are nine separate direct pathways leading from exam preparation to DI and TfU practices and numerous indirect paths that link exam preparation, on the one hand, to all of the remaining instructional practices, on the other.

The findings of both the LPS in Singapore and CORE 2 study have motivated researchers at the NIE, Singapore, to embark on a very large-scale study to explore 
the enacted school mathematics curriculum in Singapore secondary schools. In the next section we provide a brief of the study.

\section{A Study of the Enacted School Mathematics Curriculum}

This study is funded by the Ministry of Education through the Office of Education Research at the NIE, helmed by professors Berinderjeet Kaur and Toh Tin Lam and involving six other colleagues. It is the first of its type, i.e., a programmatic research project at NIE. Two studies with distinct goals form the programmatic research. The studies and their respective goals are as follows:

Study 1: Pedagogies adopted by mathematics-experienced teachers when enacting the curriculum

- How do teachers introduce and engage students in constructing conceptual knowledge?

- How do teachers engage students in developing fluency with skills in computing?

- What mathematical processes are used and developed by teachers?

- How do the teachers imbue desired attitudes for the learning of mathematics amongst their students?

Study 2:

- How do teachers select instructional materials?

- How do teachers modify the selected instructional materials?

- What are the characteristics of instructional materials that will

(i) help teachers enact worthy instructional goals of teaching mathematics and

(ii) help students improve desirable outcomes?

In a nutshell, the project examines the pedagogies commonly adopted by competent secondary mathematics teachers. It also documents the match between the enacted and planned curriculum in the classrooms of competent secondary mathematics teachers. In the context of the study, 'competent' teachers are those considered by the local community to be teachers whose pedagogical practices are exemplary and result in good student learning outcomes. Over a period of two years, 30 competent mathematics teachers and their students will participate in the study.

The project adopts the complementary accounts methodology, similar to that of the LPS (Clarke, 1998). A sequence of about 6-10 lessons from each teacher encompassing a complete mathematical topic will be video-recorded using a three-camera approach. The video cameras will be trained on the teacher, the whole class and selected pairs of students referred to as focus students. After each lesson, on the same day, the focus students will be interviewed about their learning during the lesson. The interview will also be video-recorded. Students' work done during 
the lesson and interview may be digitized for use of the project. Teachers will also be interviewed a few times during their participation in the study.

As the teachers studied in the project are the upper bound of the mathematics teacher fraternity, the findings will help us understand the why, what and how of mathematics learning in our secondary schools. In addition, the findings will help mathematics educators at the NIE shape the preparation of pre-service teachers and development of in-service teachers. We look forward to sharing the findings of the study at future international meetings.

\section{Conclusion}

This paper has shared with readers the very humble beginnings of mathematics classroom studies in Singapore by the author and her colleagues at the NIE- the sole teacher education institute in the country. It has also, through the very small segments of the data and findings of studies carried out in Singapore mathematics classrooms, shown how images of teaching are affected by the type of lenswide-angle or close-up. Lastly, the paper has also initiated the conversation about the myth of the East Asian mathematics-classroom teaching stereotype by examining models of mathematics instruction in Singapore schools. The present study, a study of the enacted school mathematics curriculum underway in Singapore, aims to paint a comprehensive portrait of mathematics instruction in Singapore schools.

\section{References}

Beaton, A. E., Mullis, I. V. S., Martin, M. O., Gonzalez, E. J., Kelly, D. L., \& Smith, T. A. (1997). Mathematics achievement in the middle school years: IEA'S third international mathematics and science study. Chestnut Hill, MA: TIMSS \& PIRLS International Study Centre, Boston College.

Chang, A. S. C., Kaur, B., Koay, P. L., \& Lee, N. H. (2001). An exploratory analysis of current pedagogical practices in primary mathematics classrooms. The NIE Researcher, 192, 7-8.

Clarke, D., Keitel, C. \& Shimizu, Y. (2006). The Leaner's perspective study. In D. Clarke, C. Keitel \& Y. Shimizu (Eds.), Mathematics classrooms in twelve countries: The insider's perspective (pp. 1-14). The Netherlands, Rotterdam: Sense Publishers.

Clarke, D. J. (1998). Studying the classroom negotiation of meaning: Complementary accounts methodology. In A. Teppo (Ed.), Qualitative research methods in mathematics education, monograph number 9 of the Journal for Research in Mathematics Education (pp. 98-111). Reston, VA: NCTM.

Hiebert, J., Gallimore, R., Garnier, H., Givvin, K. B., Hollingsworth, H., Jacobs, J., ..., Stigler, J. (2003). In Teaching mathematics in seven countries-Results from the TIMSS 1999 video study. U.S. Department of Education, National Centre for Education Statistics.

Hogan, D., Chan, M., Rahim, R., Kwek, D., Aye, K. M., Loo, S. C., et al. (2013a). Assessment and the logic of instructional practice in secondary 3 english and mathematics classrooms in Singapore. Review of Education, 1, 57-106. 
Hogan, D., Towndrow, P., Chan, M., Kwek, D., \& Rahim, R. A. (2013a). In CRPP Core 2 research program: Core 2 interim final report. Singapore: National Institute of Education.

Kaur, B. (2008). Teaching and learning of mathematics: What really matters to teachers and students? ZDM Mathematics Education, 40, 951-962.

Kaur, B. (2009). Characteristics of good mathematics teaching in Singapore grade 8 classrooms: A juxtaposition of teachers' practice and students' perception. ZDM Mathematics Education, 41, 333-347.

Kaur, B., \& Low, H. K. (2009). Student perspective on effective mathematics pedagogy: Stimulated recall approach study. Singapore: National Institute of Education.

Kaur, B., \& Yap, S. F. (1997). Kassel project (NIE-Exeter Joint Study). Second Phase (October 95-June 96). Singapore: National Institute of Education.

Leung, F. K. S. (2001). In search of an East Asian identity in mathematics education. Educational Studies in Mathematics, 47(1), 35-41.

Mullis, I. V. S., Martin, M. O., Beaton, A. E., Gonzalez, E. J., Kelly, D. L., \& Smith, T. A. (1997). Mathematics achievement in the primary school years: IEA'S third international mathematics and science study. Chestnut Hill, MA: TIMSS \& PIRLS International Study Centre, Boston College.

Mullis, V. S. I., Martin, M. O., \& Foy, P. (2008). TIMSS 2007 international mathematics report. Chestnut Hill, MA: TIMSS \& PIRLS International Study Centre, Boston College.

Mullis, I. V. S., Martin, M. O., Foy, P., \& Arora, A. (2012). TIMSS 2011 International results in mathematics. Chestnut Hill, MA: TIMSS \& PIRLS International Study Center, Boston College.

Mullis, I. V. S., Martin, M. O., Gonzalez, E. J., \& Chrostowski, S. J. (2004). International mathematics report: Findings from IEA'S trends in international mathematics and science study at the fourth and eighth grades. Chestnut Hill, MA: TIMSS \& PIRLS International Study Centre, Boston College.

Mullis, I. V. S., Martin, M. O., Gonzalez, E. J., Gregory, K. D., Garden, R. A., O’Connor, K. M., et al. (2000). TIMSS 1999 (TIMSS-R) International mathematics report findings from IEA's repeat of the third international mathematics and science study at the eighth grade. Chestnut Hill, MA: TIMSS \& PIRLS International Study Centre, Boston College.

Stigler, J. W., \& Hiebert, J. (1999). The teaching gap-Best ideas from the world's teachers for improving education in the classroom. The Free Press.

Stodolsky, S. S. (1988). The subject matters: Classroom activity in math and social studies. Chicago: The University of Chicago Press.

Open Access Except where otherwise noted, this chapter is licensed under a Creative Commons Attribution 4.0 International License. To view a copy of this license, visit http://creativecommons. org/licenses/by/4.0/.

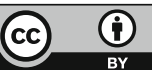

